Final version as preprint only

\title{
Trends in anatomical publications indexed in MEDLINE
}

Jelle Stans ${ }^{1 *}$

${ }^{1}$ Institute for Globally Distributed Open Research and Education, Beringen, Belgium

* Jelle.Stans@igdore.org

Keywords: Publications, Anatomy, MEDLINE 
Publishing research findings in peer-review journals is essential to distribute these results to the scientific community. For the anatomical sciences, this is especially true since a good understanding of anatomy is essential for clinical practice ${ }^{1}$. The current preprint aims to describe some trends in anatomical research indexed in the Medline database.

\section{Number of publications}

On the 8th of October 2021, 403,217 articles were indexed in Medline (accessed through PubMed) for the anatomy MeSH term. The evolution of the number of indexed papers in PubMed per year is shown in figure 1. Until 1962, less than 1000 articles were indexed each year. Starting from 1981, there was a steady increase until 16,006 publications were indexed in 2005. Interestingly, from 2011 onwards, there has been a marked decrease to 5586 publications in 2020. The numbers for 2021 should be investigated later to confirm whether this decrease will continue. Further research should be conducted to determine the different reasons for this drop in studies published.

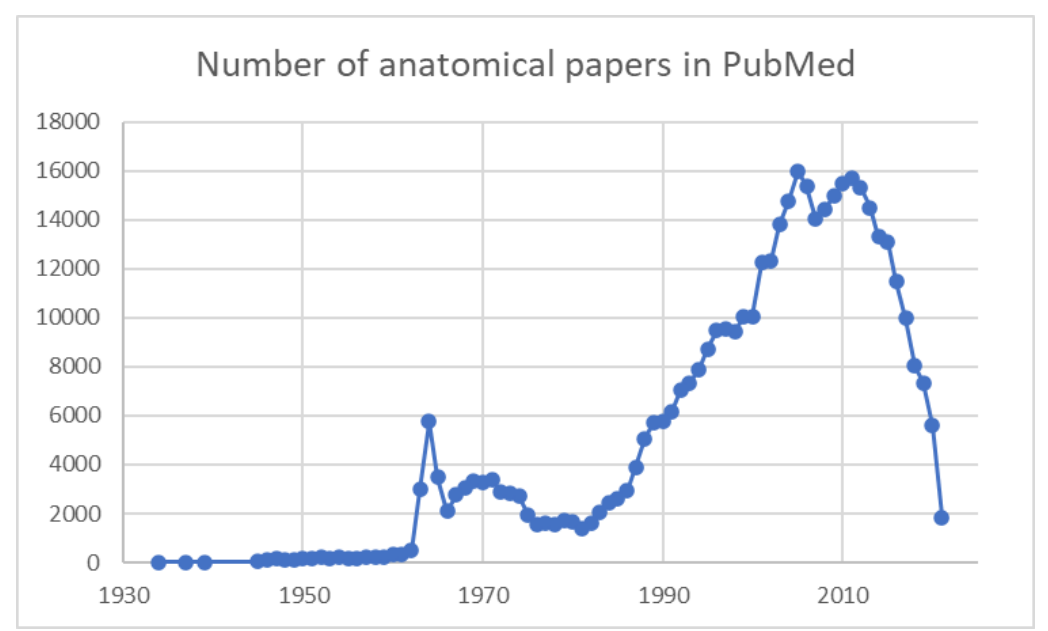

Figure 1: Number of papers indexed with the anatomy MeSH term per year

\section{Article scope}

A first subject that was discussed often was anatomical education. This included papers ranging from describing the best teaching practices ${ }^{2}$ to knowledge retention ${ }^{3}$. Case reports ${ }^{4}$ and observational studies ${ }^{5}$ on specific anatomical variations and other topics were also published. Other publications described newly identified structures ${ }^{6}$.

\section{Study type}

Interestingly, a relatively large proportion of 35,046 articles (8.70\%) concerned case reports. This could be caused by interesting anatomical variations and findings in specific patients being published as case reports. In contrast, only a small proportion of 3,294 (<1\%) of the indexed articles concerned clinical trials. This can probably be explained by the fact that anatomy by itself is not necessarily a clinical discipline. The proportion of clinical trials in the oncology search results was almost $4 \%$.

\section{Paper accessibility}

103,806 out of the 403,217 total articles $(25.75 \%)$ had a free full text available. This is comparable with the results of a comparable search for other disciplines such as oncology (25.54\%) and pneumology (32.82\%). Several discipline-specific open access journals such as the Romanian journal of Functional and Clinical, Macro- and Microscopical Anatomy and of Anthropology and European Journal of Anatomy are available for researchers that want to make their work freely available. These journals are often published by anatomical societies, with the above journals, for example, being 
published by the Romanian Society of Anatomy and Spanish Association of Anatomy respectively. It should be noted that members of the Anatomical Society and the American Association of Anatomists have access to the journals published by their societies, including the Journal of Anatomy and the Anatomical Record.

\section{References}

1. Smith CF, Mathias HS. What impact does anatomy education have on clinical practice? Clin Anat. 2011 Jan;24(1):113-9. doi: 10.1002/ca.21065. PMID: 20949490.

2. Estai M, Bunt S. Best teaching practices in anatomy education: A critical review. Ann Anat. 2016 Nov;208:151-157. doi: 10.1016/j.aanat.2016.02.010. Epub 2016 Mar 17. PMID: 26996541.

3. Jurjus RA, Lee J, Ahle S, Brown KM, Butera G, Goldman EF, Krapf JM. Anatomical knowledge retention in third-year medical students prior to obstetrics and gynecology and surgery rotations. Anat Sci Educ. 2014 Nov-Dec;7(6):461-8. doi: 10.1002/ase.1441. Epub 2014 Mar 3. PMID: 24591485. 4. Heligman D, Sullivan RC, Millar EA. Sacral ribs. A case report. Orthopedics. 1987 Oct;10(10):143942. PMID: 3317329.

5. Fan A, Xu T, Li X, Li L, Fan L, Yang D, Li G. Using anatomical landmarks to calculate the normal joint line position in Chinese people: an observational study. J Orthop Surg Res. 2018 Oct 19;13(1):261. doi: 10.1186/s13018-018-0963-2. PMID: 30340645; PMCID: PMC6194602.

6. Claes S, Vereecke E, Maes M, Victor J, Verdonk P, Bellemans J. Anatomy of the anterolateral ligament of the knee. J Anat. 2013 Oct;223(4):321-8. doi: 10.1111/joa.12087. Epub 2013 Aug 1. PMID: 23906341; PMCID: PMC3791125. 